\title{
Identification of Potential Targets Linked to the Cardiovascular/Alzheimer's Axis through Bioinformatics Approaches
}

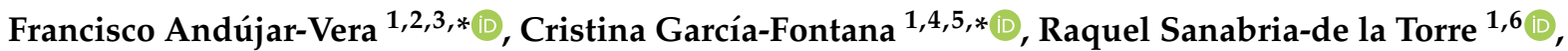 \\ Sheila González-Salvatierra ${ }^{1,4,6} \mathbb{D}$, Luis Martínez-Heredia ${ }^{1,6}$, Iván Iglesias-Baena ${ }^{7}$, \\ Manuel Muñoz-Torres 1,4,5,6,*(D) and Beatriz García-Fontana 1,4,5
}

check for updates

Citation: Andújar-Vera, F.; García-Fontana, C.; Sanabria-de la Torre, R.; González-Salvatierra, S.; Martínez-Heredia, L.; Iglesias-Baena, I.; Muñoz-Torres, M.; García-Fontana, B. Identification of Potential Targets Linked to the

Cardiovascular/Alzheimer's Axis through Bioinformatics Approaches. Biomedicines 2022, 10, 389 . https: / / doi.org/10.3390/ biomedicines 10020389

Academic Editors: Manfredi Tesauro and Annalisa Noce

Received: 7 January 2022

Accepted: 4 February 2022

Published: 6 February 2022

Publisher's Note: MDPI stays neutral with regard to jurisdictional claims in published maps and institutional affiliations.

Copyright: (C) 2022 by the authors. Licensee MDPI, Basel, Switzerland. This article is an open access article distributed under the terms and conditions of the Creative Commons Attribution (CC BY) license (https:// creativecommons.org/licenses/by/ $4.0 /)$.
1 Instituto de Investigación Biosanitaria de Granada, 18012 Granada, Spain; raquelsanabriadlt@gmail.com (R.S.-d.l.T.); sgsalvatierra@ugr.es (S.G.-S.); luismh95@gmail.com (L.M.-H.); bgfontana@fibao.es (B.G.-F.)

2 Department of Computer Science and Artificial Intelligence, University of Granada, 18071 Granada, Spain

3 Andalusian Research Institute in Data Science and Computational Intelligence (DaSCI Institute), 18014 Granada, Spain

4 Endocrinology and Nutrition Unit, University Hospital Clínico San Cecilio of Granada, 18016 Granada, Spain

5 CIBERFES, Instituto de Salud Carlos III, 28029 Madrid, Spain

6 Department of Medicine, University of Granada, 18016 Granada, Spain

7 Fundación para la Investigación Biosanitaria de Andalucía Oriental-Alejandro Otero (FIBAO), 18012 Granada, Spain; iglesiasbaena@hotmail.com

* Correspondence: fandujar@ibsgranada.es (F.A.-V.); cgfontana@hotmail.com (C.G.-F.); mmt@mamuto.es (M.M.-T.); Tel.: +34-958023460 (F.A.-V. \& C.G.-F.); +34-958-246124 (M.M.-T.)

\begin{abstract}
The identification of common targets in Alzheimer's disease (AD) and cardiovascular disease (CVD) in recent years makes the study of the CVD/AD axis a research topic of great interest. Besides aging, other links between CVD and AD have been described, suggesting the existence of common molecular mechanisms. Our study aimed to identify common targets in the CVD/AD axis. For this purpose, genomic data from calcified and healthy femoral artery samples were used to identify differentially expressed genes (DEGs), which were used to generate a protein-protein interaction network, where a module related to AD was identified. This module was enriched with the functionally closest proteins and analyzed using different centrality algorithms to determine the main targets in the CVD/AD axis. Validation was performed by proteomic and data mining analyses. The proteins identified with an important role in both pathologies were apolipoprotein $\mathrm{E}$ and haptoglobin as DEGs, with a fold change about +2 and -2 , in calcified femoral artery vs healthy artery, respectively, and clusterin and alpha-2-macroglobulin as close interactors that matched in our proteomic analysis. However, further studies are needed to elucidate the specific role of these proteins, and to evaluate its function as biomarkers or therapeutic targets.
\end{abstract}

Keywords: Alzheimer's disease; bioinformatics; cardiovascular disease; differentially expressed genes; hubs; protein-protein interaction network

\section{Introduction}

Cardiovascular disease (CVD) is the leading cause of mortality worldwide. The World Health Organization (WHO) estimates that in 2015 (the latest year for which data have been published), 31\% of all deaths worldwide were due to CVD. CVD is mainly caused by the development of atherosclerosis, and encompasses coronary heart disease, peripheral arterial disease and cerebrovascular disease. There are several well-known risk factors that increase the likelihood of developing CVD, such as hypertension, smoking, decreased serum high-density-lipoprotein (HDL), increased serum low-density lipoprotein (LDL), diabetes, sedentary lifestyle, obesity, family history, age, and alcohol consumption. Scientific evidence has shown that CVD could be related to other pathologies which a priori might 
appear to be independent of each other, such as bone [1-3] or neurological disorders [4,5]. In this context, experimental and clinical studies on brain ischemia provide ample evidence that ischemia is involved in the development of the phenotype and genotype of Alzheimer's disease (AD) [6].

$\mathrm{AD}$, defined by the $\mathrm{WHO}$ as a neurodegenerative disease of unknown etiology characterized by a progressive deterioration of memory and cognitive function [7], accounts for approximately $50-75 \%$ of all cases of dementia. According to worldwide statistics from the Global Burden Disease Study, AD was among the 50 main causes of mortality in the period between 1990 and 2013. There are currently about 34 million people with AD worldwide and the prevalence is expected to triple in the next 40 years due to demographic changes and longer life expectancy, which translates to 1 in 85 people worldwide being affected with AD by 2050 [8]. Risk factors that have been associated with the development of AD include female gender [9], age [10], smoking [11], obesity [12,13] and diabetes mellitus [14], among others.

Traditionally, attempts to understand AD have focused on trying to predict the presence of amyloid plaques and neurofibrillary tangles, and on understanding the origin of their accumulation. However, there is growing scientific evidence linking it to other molecular determinants, such as apolipoprotein E, lipid metabolism, neuroinflammation and mitochondrial function, that appear to play a key role in the development of AD [15].

Although aging is the most important risk factor for the development of CVD and $\mathrm{AD}$ [16], cardiovascular-related risk factors play a key role in cognitive disorders by their involvement in the amyloid clearance process. For instance, several cardiovascular risk factors, such as hyper and hypotension, heart failure, coronary artery disease, stroke, emboli and atherosclerosis, have been reported as potential factors with a role in cognitive decline in AD patients [17-19].

Similarly, obesity, a major CVD risk factor, has been consistently associated with the presence of dementia, as well as a higher midlife body mass index, which proportionally increases AD risk [20].

On the other hand, brain alterations in $\mathrm{AD}$ patients are often accompanied by vascular alterations, including blood vessels with collapsed or degenerated endothelia in more than $90 \%$ of cases [21]. Other studies have reported the presence of amyloid deposits in distal organs, vessels and the heart of AD patients, causing damage to these organs and promoting the development of cardiovascular complications, especially heart diastolic dysfunction $[18,19,22]$. In addition, CVD patients and AD patients share common brain structural alterations [22].

Scientific evidences from genetic studies have also supported the link between CVD and AD [23]. The study of Ray et al. (2008), through a computational analysis, shows the co-existence in a single functional module of genes typically related to $\mathrm{AD}$ and genes associated with CVD. This study shows the existence of extensive links between AD and CVD in terms of co-expression and co-regulation [24]. Moreover, genetic meta-analyses of $\mathrm{AD}$ have identified new risk loci involved in lipid processing highly related to CVD [25].

In the therapeutic context, there is some scientific evidence which supports this link between CVD and AD. Thus, a beneficial effect has been observed in the use of certain direct oral anticoagulants, such as dabigatran, rivaroxaban and apixaban, for the treatment of cerebral amyloid angiopathy. These molecules have therefore been proposed to improve the vascular-mediated progression of neurodegenerative and cognitive changes in $\mathrm{AD}$ [26].

In this line, the evidence supports that the short- [25] and long-term [26] administration of dabigatran can induce a recovery of cognitive impairment, as well as decrease oxidative stress and neuroinflammation, and reduce the deposition of amyloid plaques [27].

Consistent with these findings, a recent article using computational tools of virtual screening and molecular docking simulations describes the use of potential multimodal agents, such as certain coagulation factors (thr and/or fXa), for the treatment of AD [26].

Furthermore, epidemiological studies have also supported the coexistence of both pathologies, showing a positive correlation between dementia and CVD in several pop- 
ulations. For instance, both disorders have been reported in $18 \%$ of a dementia autopsy series [27] and in individuals with congestive heart failure [28]. Cerebral ischemia and stroke may lead to hypoxia, amyloid beta $(\mathrm{A} \beta)$ deposition, and impairment of the bloodbrain barrier, leading to neuronal degeneration [29]. Therefore, we hypothesize that there are overlapping molecular mechanisms in CVD and AD.

Considering the high proportion of patients affected by CVD, it would be of great interest to identify those with a higher risk of developing cognitive deterioration in order to establish early preventive and therapeutic measures, and to delay the onset of neurological disorders. On the other hand, it could also be useful to study the potential development of cardiovascular complications in patients diagnosed with AD in order to prevent irreversible damages. Hence, we aim to characterize common factors in the development of CVD and $\mathrm{AD}$ by using bioinformatics and experimental approaches to generate biological networks to identify the essential proteins (hubs) that play a key role in the signaling and regulatory processes [30] in both pathologies. The identification of these proteins could be useful to study their potential usefulness as early biomarkers of AD in patients with CVD.

\section{Materials and Methods}

\subsection{Data Acquisition}

The first step in acquiring the data of interest was to search the GEO database (https:/ / www.ncbi.nlm.nih.gov/geo/; accessed on 19 November 2021) based on the terms "artery", "femoral artery" or "artery atherosclerosis". The requirements for selecting the datasets included the following aspects: (a) tissue samples from human femoral arteries; (b) in arteries without atherosclerotic lesions, the source had to be from healthy organ donors; and (c) at least 10 samples per group.

\subsection{Data Preprocessing and Identification of Differentially Expressed Genes (DEGs)}

The DEGs between calcified and healthy artery samples from patients aged $67 \pm 9$ years (85\% males) were analyzed using GEO2R (https:/ / www.ncbi.nlm.nih.gov/geo/geo2r/) (MD, USA), allowing the comparison of two or more datasets in a GEO series [31]. The adjusted $p$-values (adj. p) and Benjamini and Hochberg false discovery rate were applied to provide a balance between the discovery of statistically significant genes and limitations of false-positives. The absolute value of $\log$ fold change (FC) $\geq 1.5$ and adj. $p<0.05$ were considered as statistically significant.

\subsection{Protein-Protein Interaction (PPI) Network Performance and Module Analysis}

The PPI network was predicted using the Search Tool for the Retrieval of Interacting Genes/Proteins (STRING, v. 1.7.0) application [32] in the Cytoscape program (v. 3.9.0) [33]. Cytoscape is an open-source bioinformatic software platform for visualizing molecular interaction networks. The proteins that were used as seeds for the creation of the PPI network were the DEGs obtained in the previous section. For the initial exploration, the confidence score was set to high (score 0.007). Proteins without matches in the STRING database and proteins without interactions with other proteins within the network were discarded.

To find the highest connected regions based on topology within the whole PPI network, the Molecular Complex Detection (MCODE, v. 2.0.0) [34], a Cytoscape plug-in, was used. The criteria for selection were as follows: degree cutoff $=2, \mathrm{~K}$-core $=2$, node score cutoff $=0.2$ and max depth up to 100 . Thus, highly interconnected regions (modules) in the network were identified and, therefore, the functionality of the modules was studied in depth.

Subsequently, the analyses of genes associated with diseases in these modules and the Gene Ontology (GO) enrichment analysis were performed using the DAVID online database (https:/ / david.ncifcrf.gov/home.jsp) (MD, USA) to identify the modules of interest related to AD. 


\subsection{Construction of a Secondary Related PPI Network and Identification of Hubs}

The proteins belonging to the module of interest identified in the previous section were selected for the construction of a new PPI network. Similar to the prediction of the first PPI network, Cytoscape's STRING application was used. This secondary PPI network kept the same high confidence score of 0.007 . In addition, the maximum number of interactors to display was set in 50 .

Based on the open-source platform Cytoscape, a convenient app called CytoNCA (v.2.1.6) [35] for network centrality analysis was used to explore the secondary PPI network. The two algorithms used were Degree and Betweenness, to identify important nodes in a large number of interactions and the total number of shortest pathways between two nodes, respectively. Through this tool, the most important nodes within the network (called hubs) were identified. Additionally, a KEGG and GO enrichment analysis was performed in the DAVID database on the secondary PPI network. This analysis allowed for the identification of the most significant GO terms and pathways for this set of proteins.

\subsection{Validation of Target Proteins by Data-Mining and Proteomic Analysis}

Factors associated with AD were identified using DisGeNET (http:/ / www.DisGeNET. org/home/) (Spain) [36], a discovery platform which integrates information on GDAs from several public data sources and the scientific literature about gene expression, biomarkers, clinical phenotype associations with the corresponding diseases, variant-disease associations, and single nucleotide polymorphisms. The current version of, DisGeNET (v.7.0) (Spain) contains 1,134,942 GDAs between 21,671 genes and 30,170 diseases and traits.

A proteomic analysis of calcified femoral artery samples from 7 patients diagnosed with type 2 diabetes, according to the criteria established in the American Diabetes Association (2011), was performed to validate the results obtained through bioinformatic approaches. The cohort of patients was represented by adult males (mean age $74 \pm 10$ years) who were monitored at the University Hospital Clínico San Cecilio of Granada. All patients were diagnosed with critical ischemia, according to the consensus document on peripheral disease TASC II [37], with an indication of lower limb amputation. Briefly, protein samples from the vascular tissue were extracted, followed by concentration, clean up and digestion standard procedures. Then, protein separation and identification were performed using nano-scale liquid chromatographic tandem mass spectrometry (nLC-MS/MS) and Proteome Discoverer, respectively, as previously reported [38]

The detailed protocol is extensively described in the Supplementary Materials.

Both the disease-associated indicators obtained from DisGeNET and the proteins identified in the proteomic analysis were confronted with the list of proteins of interest obtained in the PPI network.

The workflow schematic performed in this study is summarized in Figure 1. 

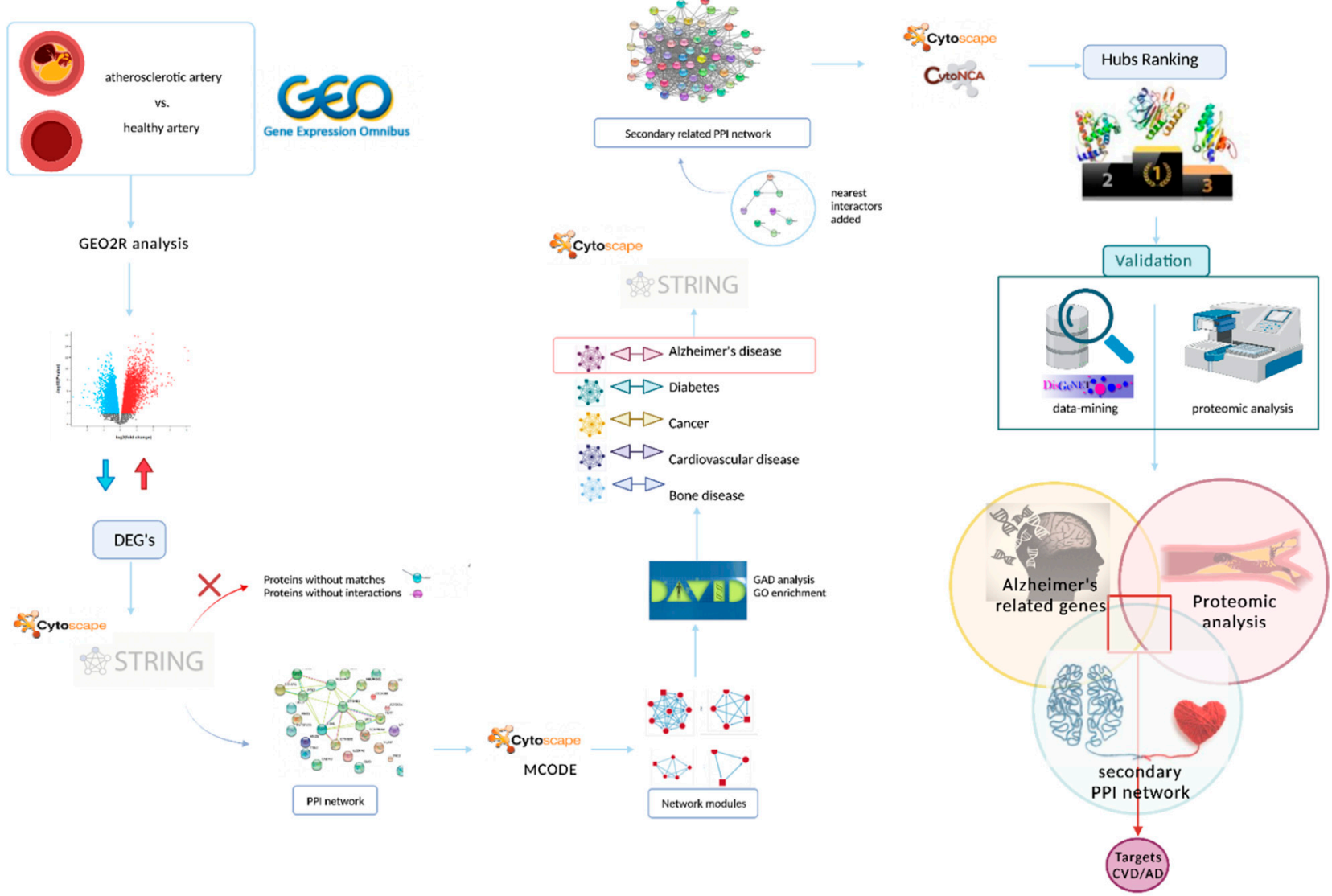

Figure 1. Flowchart of the methodology used. This scheme summarizes the whole process, from the search in databases of CVD and AD related targets to the validation by data-mining and proteomic analysis. DEG's: differential expressed genes; PPI: protein-protein interaction; CVD: cardiovascular disease; AD: Alzheimer's disease. Created with BioRender.com.

\section{Results}

\subsection{Data Acquisition}

After an exhaustive search, the microarray expression profile dataset GSE100927 were downloaded from the GEO database, which was based on GPL17077 Agilent-039494 SurePrint G3 Human GE v2 8x60K Microarray 039381. The GSE100927 dataset included 26 atheromatous plaque samples harvested from patients undergoing femoral endarterectomy and 12 healthy artery samples free of atherosclerotic lesions obtained from organ donors [39].

\subsection{Data Preprocessing and Identification of DEGs}

The selection of DEGs analyzed with GEO2R between the femoral artery with atherosclerotic lesions and the healthy femoral arteries are presented in a volcano diagram (Figure 2). A total of 163 DEGs were identified in atheromatous plaques compared to controls, including 143 upregulated and 20 downregulated DEGs (Supplementary Table S1). 


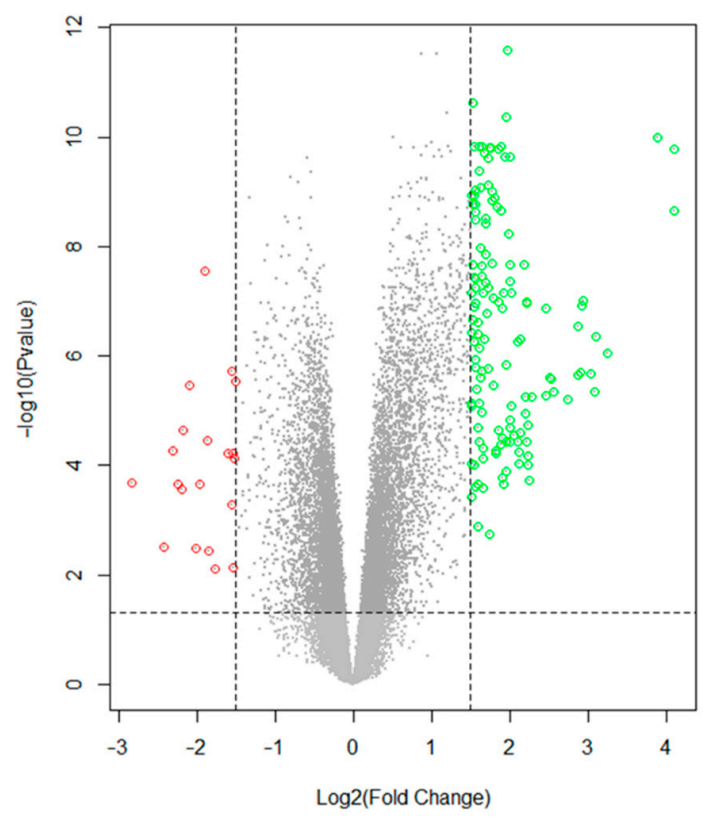

Figure 2. Volcano plot of differentially expressed genes (DEGs) between calcified femoral artery samples and control samples. The data were obtained from dataset GSE100927 from the GEO database. From left to right: downregulated genes (red dots), non-significant genes (grey dots, bottom panel), significant genes that do not meet the established fold change value (dark gray dots, upper panel) and upregulated genes (green dots). Log fold change $\geq 1.5$ and adjusted $p$-value $<0.05$ were considered as the cutoff for statistical significance.

\subsection{PPI Network Performance and Module Analysis}

The 163 DEGs obtained in the previous section were entered into the STRING application. Once the filters were set for the whole dataset, a PPI network including 79 proteins (nodes) and 166 interactions (edges) resulted (Figure 3A).
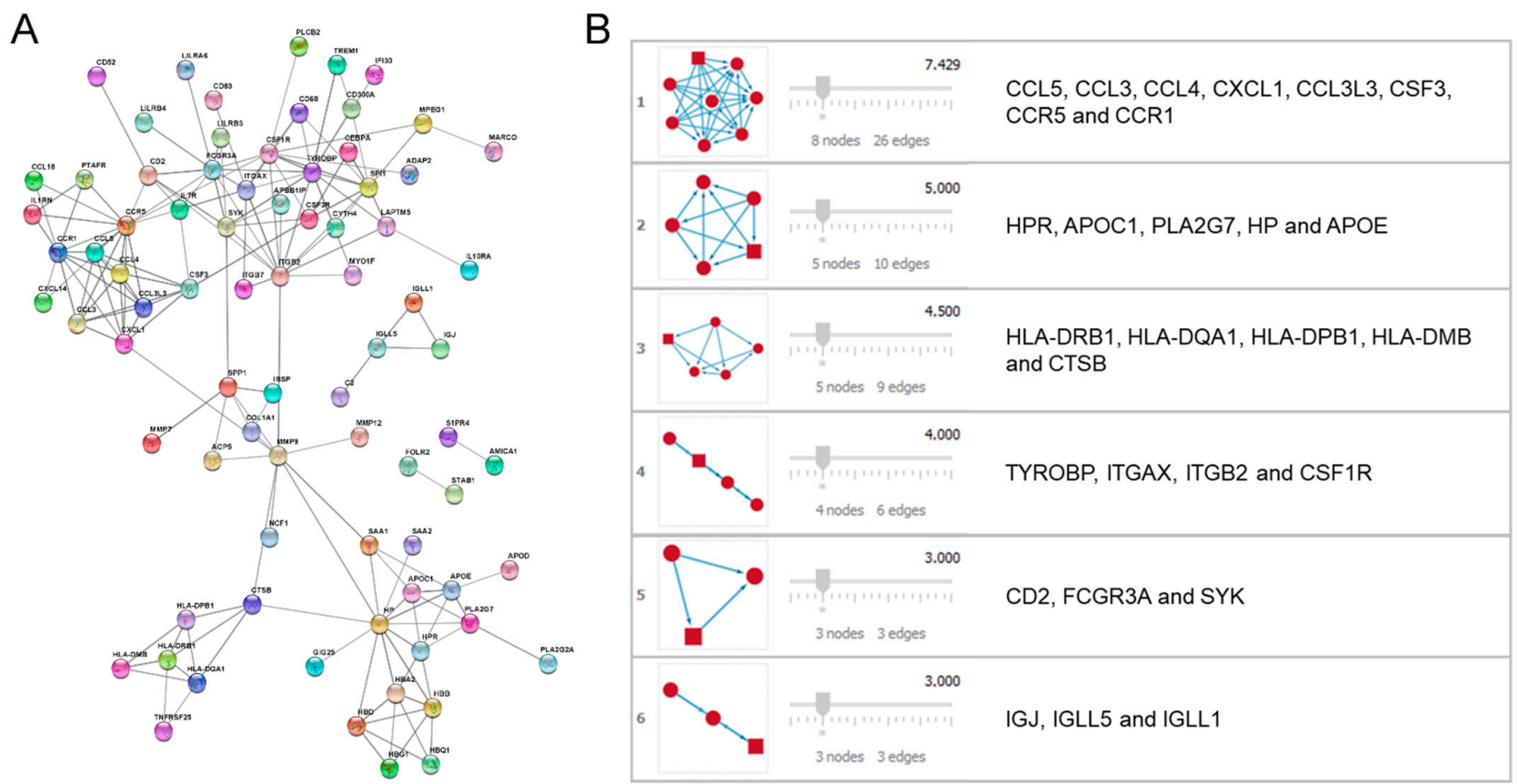

Figure 3. (A) Protein-protein interaction (PPI) network generated from differentially expressed genes (DEGs) obtained through the STRING application. (B) Network modules predicted through MCODE software. 
The analysis performed by MCODE for the determination of the network modules resulted in a prediction of six modules including highly connected nodes (Figure 3B).

Each of the modules obtained was analyzed through the DAVID enrichment tool, and only the module most related to AD was selected (module 2, Figure 3B). Table 1 shows the enrichment results of module 2 obtained after analysis by the DAVID tool. The other modules did not offer obvious linkage with the pathologies under study.

Table 1. Enrichment results of the module most related to Alzheimer's disease (Module 2).

\begin{tabular}{|c|c|c|c|c|}
\hline Category & Term & $\%$ & $p$-Value & Genes \\
\hline GAD_DISEASE & cardiovascular disease & 80 & $3.56 \times 10^{-7}$ & APOC1, HP, APOE, PLA2G7 \\
\hline GAD_DISEASE & atherosclerosis, coronary & 80 & $6.64 \times 10^{-6}$ & APOC1, HP, APOE, PLA2G7 \\
\hline GOTERM_CC_DIRECT & GO:0005576 extracellular region & 100 & $6.07 \times 10^{-5}$ & APOC1, HP, HPR, APOE, PLA2G7 \\
\hline GAD_DISEASE & cholesterol & 80 & $1.38 \times 10^{-4}$ & APOC1, HPR, APOE, PLA2G7 \\
\hline GAD_DISEASE & $\begin{array}{c}\text { coronary disease; coronary heart } \\
\text { disease }\end{array}$ & 60 & $1.61 \times 10^{-4}$ & APOC1, APOE, PLA2G7 \\
\hline GOTERM_CC_DIRECT & GO:0072562 blood microparticle & 60 & $4.10 \times 10^{-4}$ & HP, HPR, APOE \\
\hline GAD_DISEASE & familial dysbetalipoproteinemia & 40 & $6.17 \times 10^{-4}$ & APOC1, APOE \\
\hline GOTERM_BP_DIRECT & $\begin{array}{l}\text { GO:0034447 very-low-density } \\
\text { lipoprotein particle clearance }\end{array}$ & 40 & $7.14 \times 10^{-4}$ & APOC1, APOE \\
\hline GOTERM_BP_DIRECT & $\begin{array}{l}\text { GO:0006898 receptor-mediated } \\
\text { endocytosis }\end{array}$ & 60 & $7.22 \times 10^{-4}$ & HP, HPR, APOE \\
\hline GAD_DISEASE & type 2 diabetes; edema; rosiglitazone & 100 & $8.23 \times 10^{-4}$ & APOC1, HP, HPR, APOE, PLA2G7 \\
\hline GAD_DISEASE & $\begin{array}{c}\text { coronary disease; diabetes } \\
\text { complications; } \\
\text { hypercholesterolemia; } \\
\text { hypertension; myocardial infarction }\end{array}$ & 40 & $9.25 \times 10^{-4}$ & APOC1, APOE \\
\hline GOTERM_MF_DIRECT & GO:0030492 hemoglobin binding & 40 & $9.48 \times 10^{-4}$ & $\mathrm{HP}, \mathrm{HPR}$ \\
\hline GAD_DISEASE & $\begin{array}{c}\text { cholesterol; coronary heart disease; } \\
\text { lipoproteins }\end{array}$ & 40 & $1.23 \times 10^{-3}$ & APOC1, APOE \\
\hline GAD_DISEASE & cardiovascular diseases & 60 & $1.24 \times 10^{-3}$ & APOC1, APOE, PLA2G7 \\
\hline GOTERM_MF_DIRECT & $\begin{array}{c}\text { GO:0060228 phosphatidylcholine- } \\
\text { sterol O-acyltransferase activator } \\
\text { activity }\end{array}$ & 40 & $1.42 \times 10^{-3}$ & APOC1, APOE \\
\hline GOTERM_BP_DIRECT & $\begin{array}{c}\text { GO:0034382 chylomicron remnant } \\
\text { clearance }\end{array}$ & 40 & $1.43 \times 10^{-3}$ & APOC1, APOE \\
\hline GAD_DISEASE & Alzheimer's disease & 80 & $1.48 \times 10^{-3}$ & APOC1, HP, APOE, PLA2G7 \\
\hline GAD_DISEASE & memory disturbance & 40 & $1.85 \times 10^{-3}$ & APOC1, APOE \\
\hline
\end{tabular}

Category indicates the classification shown by the DAVID database; \% indicates the proportion of proteins of the module involved in the corresponding category; $p$-value consists of the modified Fisher exact $p$-value for the enrichment performed; APOC1: apolipoprotein C1; HP: haptoglobin; APOE: apolipoprotein E; PLA2G7: platelet-activating factor acetylhydrolase; HPR: haptoglobin related-protein.

\subsection{Enrichment of the Secondary PPI Network and Identification of Hubs}

Once the AD-related module was identified, the proteins forming the module were selected for visualization (Figure $4 \mathrm{~A}$ ) and enriched with the 50 functionally nearest proteins (Figure 4B).

For the determination of the most important proteins (hubs) from the secondary PPI network, CytoNCA was used by applying the "Betweenness" and "Degree" centrality algorithms. Table 2 shows the result of the 15 proteins with the highest centrality value within this secondary PPI network derived from the initial module 2. 


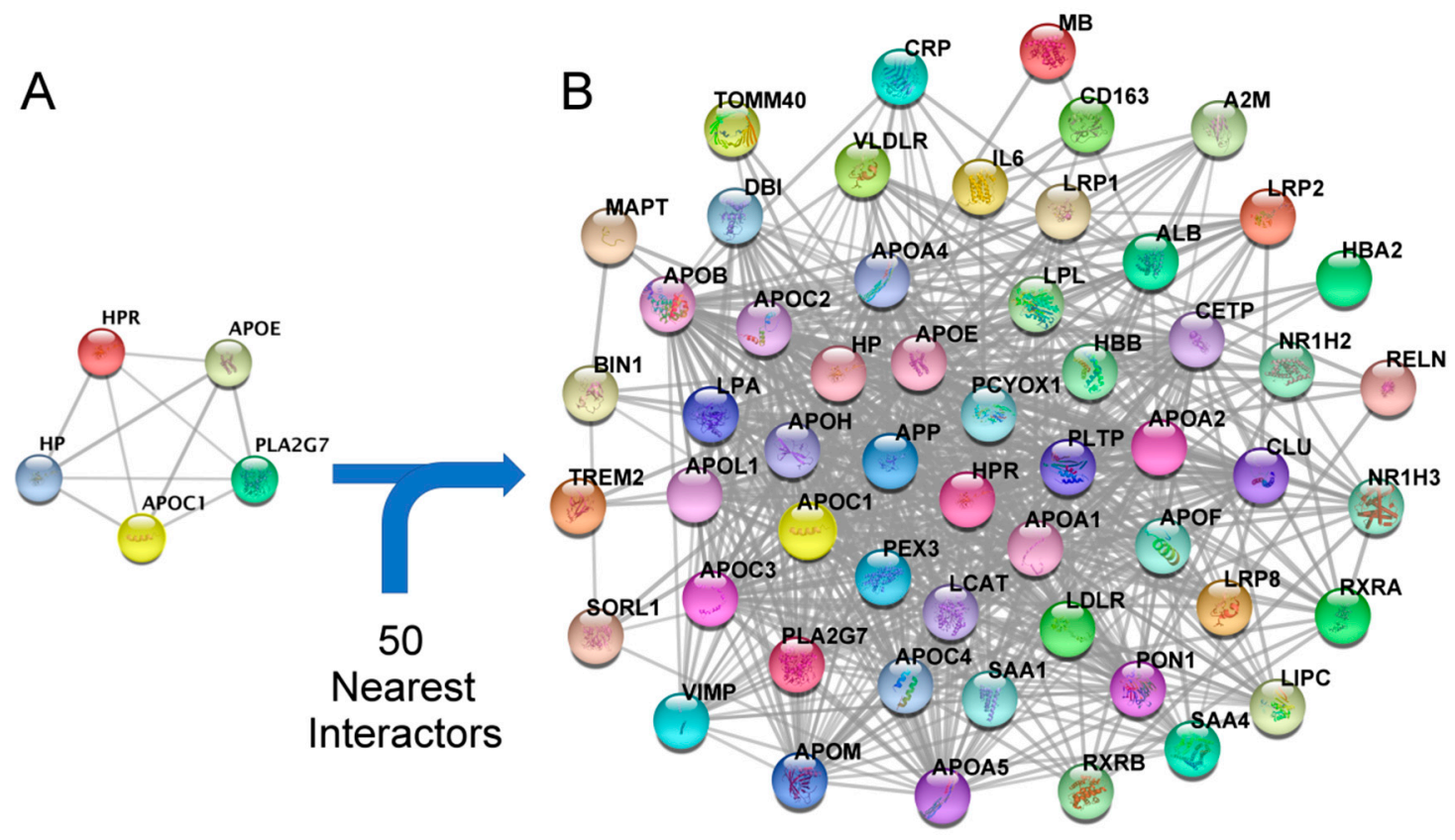

Figure 4. (A) Proteins belonging to module 2 (APOC1, HP, HPR, APOE and PLA2G7). (B) Proteinprotein interaction (PPI) network adding the 50 functionally nearest proteins to module 2 .

Table 2. List of hubs of the secondary PPI network according to "Betweenness" and "Degree" algorithms from CytoNCA.

\begin{tabular}{cccc}
\hline Symbol & Description & Degree & Betweenness \\
\hline APOE & Apolipoprotein E & 50.0 & 416.64447 \\
APOA1 & Apolipoprotein A1 & 42.0 & 118.15003 \\
APOC2 & Apolipoprotein C2 & 40.0 & 71.67373 \\
APP & Amyloid Beta Precursor Protein & 39.0 & 196.27913 \\
APOA2 & Apolipoprotein A2 & 39.0 & 57.75081 \\
APOC1 & Apolipoprotein C1 & 39.0 & 97.92878 \\
APOB & Apolipoprotein B & 38.0 & 47.32024 \\
CLU & Clusterin & 37.0 & 84.87135 \\
APOC3 & Apolipoprotein C3 & 37.0 & 36.22977 \\
PLTP & Phospholipid Transfer Protein & 36.0 & 41.08785 \\
CETP & Cholesteryl Ester Transfer Protein & 36.0 & 43.38615 \\
HP & Haptoglobin & 36.0 & 234.20578 \\
APOA4 & Apolipoprotein A4 & 35.0 & 25.99814 \\
APOC4 & Apolipoprotein C4 & 33.0 & 32.60615 \\
APOA5 & Apolipoprotein A5 & 33.0 & 416.64447 \\
\hline
\end{tabular}

GO and KEGG enrichment analysis shows that most genes of the secondary PPI network are involved in pathways related to lipid metabolism, and inflammation processes, as well as immune response. Some of them also appear to be involved in AD-related pathways (Supplementary Table S2).

\subsection{Validation of Target Proteins by Data-Mining and Proteomic Analysis}

Both datamining-based techniques and laboratory proteomic analysis techniques were used for the validation.

The genes associated with AD were obtained through the DisGeNET platform. Once the cutoff threshold was set at 0.3 , the gene-disease associations (GDAs) were included in the Venn diagram (Figure 5A). A total of 124 indicators of AD were identified in this step. 


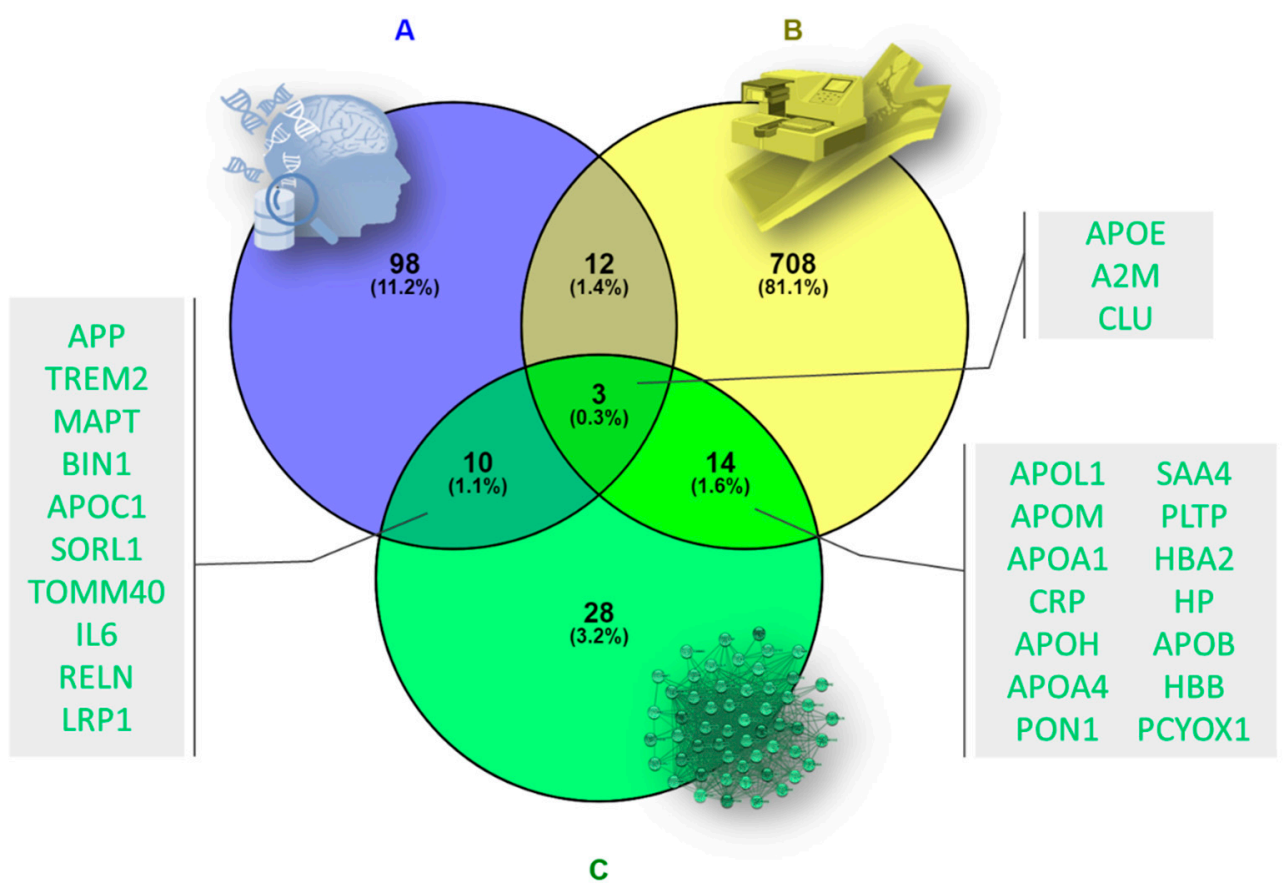

Figure 5. Venn diagram showing (A) the set of AD-related proteins obtained from DisGeNET, (B) the set of proteins identified in the proteome of calcified femoral arteries samples, and $(\mathrm{C})$ the set of proteins belonging to the secondary protein-protein interaction (PPI) network derived from the initial AD-related module 2. APP: amyloid precursor protein; TREM2: triggering receptor expressed on myeloid cells 2; MAPT: microtubule-associated protein tau; BIN1: bridging integrator 1; APOC1: apolipoprotein C1; SORL1: sortilin-related receptor 1; TOMM40: translocase of outer mitochondrial membrane 40; IL6: interleukin 6; RELN: reelin; LRP1: LDL receptor-related protein 1; APOE: apolipoprotein E; A2M: alpha 2-macroglobulin; CLU: clusterin; APOL1: apolipoprotein L1; APOM: apolipoprotein M; APOA1: apolipoprotein A1; CRP: C-reactive protein; APOH: apolipoprotein H; APOA4: apolipoprotein A4; PON1: paraoxonase; SAA4: serum amyloid A4; PLTP: phospholipid transfer protein; HBA2: hemoglobin subunit alpha 2; HP: haptoglobin; APOB: apolipoprotein B; HBB: hemoglobin; PCYOX1: penylcysteine oxidase 1.

On the other hand, proteomic analysis provided a total of 751 proteins, which were added to the Venn diagram. After cleaning the data by removing duplicate, empty or unmatched entries from the Uniprot database, 737 total proteins resulted (Figure 5B).

Both previous sets were confronted with the proteins constituting the AD-related secondary PPI network derived from the initial module 2 containing a total of 55 proteins (Figure 5C).

\section{Discussion}

The links between neurodegenerative disorders such as AD and CVD have not currently been elucidated. However, studies supporting this connection are gradually appearing [22]. Frequently, vascular changes accompany or even precede the development of $\mathrm{AD}$, raising the possibility that they may have a pathogenic role. The fact that aging is the most important risk factor for the development of CVD and AD [16], and that common brain structural alterations have been detected in both pathologies, suggest that there is an overlap in the molecular mechanisms shared by CVD and AD [22].

The results of this study show, through PPI network analysis and enrichment analysis, a set of genes associated with the presence of both CVD and AD. Specifically, we found three targets (APOE, CLU and A2M) closely related to both pathologies. In addition, other proteins such as haptoglobin (HP) should be considered in this context since, although we found controversial evidence, considering the consulted databases in our bioinformatics 
study we found strong evidence in the scientific literature that could link this target to the $\mathrm{CVD} / \mathrm{AD}$ axis.

It does not seem to be a coincidence that there is a relationship between CVD and $\mathrm{AD}$, since the role of lipids in the development of atherosclerosis is well known [40], and several studies have shown the key involvement of proinflammatory lipids in the formation of amyloid plaque and the aggravation of AD. Accordingly, our GO and KEGG results strongly suggest that lipid metabolism and inflammation are key factors in CVD and AD. In this context, large LDL particles have been found to correlate significantly with increased brain amyloidosis and decreased hippocampal volume [41]. Likewise, the study by Chatterjee et al. (2016) shows impaired phospholipid and sphingolipid metabolism in patients with familial forms of AD, linking the presence of these lipids with cerebrospinal fluid amyloid and tau protein [42]. On the other hand, apolipoprotein A-1 deficiency has been observed to be associated with excessive cholesterol accumulation and increased cortical exposure to amyloids, whereas apolipoprotein A-I decreases A $\beta$ aggregation and toxicity [43]. Ceramides are other lipidic molecules that have revealed their involvement in the pathogenesis of $\mathrm{AD}$, showing a clear association between plasma ceramide levels and neuropsychiatric symptoms in AD patients [44]. The study by Kim et al. (2018) revealed an impaired lipid profile in AD patients [45] and identified lipid signatures able to predict AD progression and brain atrophy [46]. Although all these findings point to a direct relationship between lipid profile with CVD and AD, clear efficacy of statins for the treatment of AD could not be established [47].

On the other hand, apolipoprotein E (APOE) is a well-known factor associated with both the development of CVD [48-50] and the development of AD [51-56]. However, there is little evidence of the involvement of this protein in the CVD/AD axis jointly [57].

In our study, we identified APOE as a key protein in the development of CVD and AD. Our results showed a strong involvement of APOE in the connection of both pathologies. GEO2R statistical analysis of previously published differential expression data between calcified femoral artery and non-calcified femoral artery data published by Steenman et al. (2018) showed that APOE is upregulated (two-fold) in calcified tissue. Likewise, at the qualitative level, we identified this protein in the proteome of calcified femoral arteries in patients with lower limb amputation. At the AD level, our analyses in DisGeNET and PPI network studies indicate a central role of APOE in the development of this pathology. The score obtained in the centrality algorithms places it as one of the most important hubs in the CVD/AD axis, supporting the important dual role of this protein.

In addition to APOE, we have been able to identify other targets that, although they show a somewhat lower score, can be classified as essential proteins in the development of CVD and AD. In this block, we can include alpha-2-macroglobulin (A2M), clusterin (CLU) or apolipoprotein $\mathrm{J}$, and haptoglobin (HP).

A2M acts as an antiprotease and is able to inactivate an enormous variety of proteinases. It acts by inhibiting plasmin and thrombin, and is therefore an inhibitor of fibrinolysis and coagulation, respectively. A2M binds numerous growth factors and cytokines, and thus acts as a transporter protein [58]. In addition, A2M seems to participate in inflammatory reactions and appears to be involved in AD. The study by Varma et al. (2017) showed a significant association of A2M in blood with markers of neuronal injury, tau and phosphorylated tau in cerebrospinal fluid, and a higher serum A2M concentration was associated with an almost three-fold increased risk of AD progression in men [59]. These data suggest that A2M could be considered a biomarker of preclinical AD, reflecting early neuronal injury [59]. At the cardiovascular level, this protein seems to be involved in the development of atherosclerosis and cardiac hypertrophy, increasing the risk of developing CVD [60]. In this context, the study by Nezu et al. (2013), revealed that an increase in serum A2M levels could be involved in the pathophysiology of acute ischemic stroke [61], which would support the role of this protein in the development of CVD.

In our results, we identified A2M in the enrichment of the initial PPI network as an essential protein with several interactions with important components in the CVD/AD 
axis. Furthermore, at the qualitative level, we identified A2M in the proteome of calcified vascular tissue samples, so these data support the dual role of this protein in CVD and AD.

CLU, also known as apolipoprotein J, is a molecular chaperone associated with cellular debris removal and apoptosis [62]. Through this function, CLU is implicated in many oxidative stress-related diseases, including neurodegenerative diseases [63], cancer [64], inflammatory diseases [65] and aging [66,67].

In the case of neurodegenerative diseases, we can highlight the role of CLU in the development of AD $[68,69]$. Together with APOE, CLU is the most expressed apolipoprotein in the central nervous system [70,71], presenting important analogies with APOE such as its presence in amyloid plaques [72,73] and its capacity to bind A $\beta$ [74,75]. Another analogy between APOE and CLU is at the functional level, such that several studies have proposed the participation of both in the elimination of $A \beta$ from the brain [76,77]. In this context, it has been proposed that CLU could be considered as a therapeutic strategy to slow the progression of AD [78]. The study by Schrijvers et al. published in JAMA in 2011 showed a significant association of plasma CLU levels with AD prevalence and severity, but not with AD incidence [79]. The meta-analysis by Yang et al. (2018) agreed with this evidence, showing that a high concentration of CLU in the plasma and brain is associated with dementia, especially in AD [80], proposing this protein as a biomarker of cognitive impairment severity [81].

Although the role of CLU in cancer or neurological diseases has been intensively studied for three decades, the physiological functions of CLU in the context of the cardiovascular system are not as well studied. In this regard, there is some scientific evidence addressing these aspects. The study by Bradley et al. (Diabetes Care, 2019), showed increased expression of CLU at the extracellular matrix (ECM) of adipose tissue in obese versus lean women through microarray studies [82]. Recently, an important role of different adipose tissue ECM components in the development of obesity-related cardiomatabolic diseases has been observed $[83,84]$. In this regard, the authors of this work proposed adipocyte-derived CLU as a novel ECM-related protein linking cardiometabolic diseases and obesity through its actions in the liver. Along these lines, the study by Won et al. (2014) proposed circulating CLU as a surrogate marker of obesity-associated systemic inflammation [85]. Since CLU is induced in vascular smooth muscle cells (VSMCs) during atherosclerosis and injuryinduced neointimal hyperplasia, the study by Kim et al. (2009), proposed the role of this protein as a protective strategy against the development of neointimal hyperplasia, rather than a causal response [86]. CLU is a ubiquitous protein, synthesized by numerous tissues and organs and with varied receptors including the HDL-cholesterol receptor, the lowdensity lipoprotein-related protein 2 (LRP/megalin), ApoER2, and the very low-density lipoprotein receptor (VLDLR), many of which are critical for cardiovascular health, and thus have recently been linked to cardiovascular and cerebrovascular effects [87-89].

Our results show the presence of CLU in the proteome of calcified vascular tissue at the qualitative level, as well as the involvement of this protein in the secondary AD-related PPI network. Our enrichment studies place it as an essential hub due to its involvement in CVD and AD. However, the controversy generated around the role of CLU makes it necessary to perform functional studies to understand the real role of CLU, and determine whether it plays a beneficial or detrimental role in the development of CVD and AD, in order to consider this protein as a potential biomarker of CVD/AD or as a therapeutic target.

Another target identified in the present study was HP, a plasma protein synthesized in the liver whose function is to bind to free hemoglobin, forming hemoglobin-haptoglobin complexes. Increased levels of HP have been observed in inflammatory processes, and it is considered an acute phase protein. In addition, HP is involved in the innate and acquired immune systems, playing a regulatory role in various stages of cellular and humoral immunity and in the release of cytokines [90]. This protein has recently been linked to neurodegenerative disorders such as AD and mild cognitive impairment. In this line, there are only two studies relating HP levels to AD severity by showing significantly higher serum levels of HP in AD, and mild cognitive impairment compared to healthy 
subjects [91,92]. To the best of our knowledge, there is no link between HP and CVD. However, our results using GEO2R suggest a two-fold downward regulation of $\mathrm{HP}$ in the calcified femoral artery compared to the non-calcified femoral artery. Furthermore, our PPI network and proteomic analyses suggest $\mathrm{HD}$ protein as a target in atherosclerosis and $\mathrm{AD}$. These findings place HP as an important hub within the CVD/AD axis.

The scarce scientific evidence of $\mathrm{HP}$ in relation to $\mathrm{AD}$, together with the non-existence of studies that functionally link it to the presence of CVD, makes $\mathrm{HP}$ an attractive candidate for the development of studies to elucidate the involvement of this protein in the CVD/AD axis. In this context, it is necessary to deepen our knowledge of these potential targets in order to broaden the range of potential biomarkers of AD and CVD for therapeutic or early diagnostic purposes.

Our study has some limitations, including the exclusion of potential targets involved in the CVD/AD axis in the bioinformatics analysis, due to establishment of a specific cut-off point. However, to overcome this limitation, an enrichment analysis was performed to avoid the loss of potential candidates. Including biological samples from patients with $\mathrm{AD}$ in future experimental work will corroborate the role of the identified proteins at the neurological level, confirming the dual participation of these proteins in the CVD/AD axis. The strength of our study lies in the generation of a strategy capable of combining and jointly exploiting the information available through different methodological approaches, generating very valuable and scientifically supported leads for the identification of new potential targets, some of which have been little explored to date, opening the door to perform further translational studies assessing the role of these proteins as biomarkers and/or therapeutic targets.

In summary, our findings suggest that the atherosclerotic processes leading to CVD could also be involved in the development of neurological disorders such as AD. The high incidence of CVD and its link with AD makes it necessary to search for new diagnostic strategies to identify high-risk patients in subclinical stages. Our study identified some potential novel targets in the CVD/AD axis, including APOE, HP, CLU and A2M, being the two first proteins up- and downregulated, respectively, in atherosclerotic vascular tissue compared with healthy vascular tissue. Although future studies are needed to confirm the dual functions of these proteins in the CVD/AD axis, this study provides valuable information for the study of the usefulness of these proteins as potential early biomarkers. This would affect future predictions of predisposition to $\mathrm{AD}$ in patients with CVD and vice versa, and facilitate the implementation of preventive and therapeutic strategies that alleviate the most aggressive effects of these disorders, and improve the quality of life of affected patients.

\section{Conclusions}

The evidence suggests that vascular pathology is a likely pathogenic contributor to age-related dementia, including $\mathrm{AD}$, and is inextricably linked to disease onset and progression. In this context, our results indicated four main targets with strong scientific evidence of involvement in the CVD/AD axis: APOE, CLU, A2M and HP. Consequently, the contribution of CVD factors highly related to neurological disorders should be considered in preventive, diagnostic, and therapeutic approaches to address one of the major health challenges of our time.

Supplementary Materials: The following supporting information can be downloaded at: https: //www.mdpi.com/article/10.3390/biomedicines10020389/s1.

Author Contributions: Conceptualization, F.A.-V., B.G.-F. and C.G.-F.; formal analysis, F.A.-V.; funding acquisition, C.G.-F., B.G.-F. and M.M.-T.; investigation, F.A.-V., C.G.-F., B.G.-F., R.S.-d.1.T., S.G.-S., L.M.-H., I.I.-B. and M.M.-T.; methodology, F.A.-V. and L.M.-H.; software, F.A.-V.; supervision, C.G.-F. and B.G.-F.; validation, F.A.-V., C.G.-F., R.S.-d.1.T. and B.G.-F.; writing-original draft, F.A.-V., C.G.-F., B.G.-F. and R.S.-d.1.T.; writing-review and editing, F.A.-V., C.G.-F., R.S.-d.I.T., S.G.-S., L.M.-H., I.I.-B., B.G.-F. and M.M.-T. All authors have read and agreed to the published version of the manuscript. 
Funding: This research was funded by Instituto de Salud Carlos III grant (PI18-00803), co-funded by the European Regional Development Fund (FEDER) and by Junta de Andalucía grant (PI-02682019). In addition, C.G.-F. and S.G.-S. are funded by postdoctoral and predoctoral fellowships from Instituto de Salud Carlos III with co-funding by FEDER (CD20/00022 and FI19/00118 respectively). R.S.d.1.T. was funded by the University of Granada with co-funding by FEDER, by grant number 8110 (Research investigator call in the framework of the youth guarantee Program)

Institutional Review Board Statement: All samples used for the study were managed by the SSPA Biobank of the University Hospital Clínico San Cecilio, in accorodance with the procedures of the SSPA Biobank approved by the Ethics Committee for Biomedical Research of Granada. The study was conducted with the approval of the Ethics Committee of the University Hospital Clínico San Cecilio of Granada and conformed to the principles of the World Medical Association Declaration of Helsinki (Project ID:0858-N-17. Research Ethics Committee of Granada Center (CEI-Granada) at 31 March 2016).

Informed Consent Statement: All subjects included in the study understood and signed the informed consent.

Data Availability Statement: The data corresponding to microarray expression profile dataset GSE100927, presented in this study are openly available in https:/ / www.ncbi.nlm.nih.gov/geo/ query/acc.cgi?acc=GSE100927, submitted by Steenman et al. (2018) [39] (doi:10.1038/s41598-018$22292-y$.). The proteomic results obtained for validation are available on request from the corresponding author.

Acknowledgments: We acknowledge Jesús Lacal Romero for the English improvement of this manuscript.

Conflicts of Interest: The authors declare no conflict of interest.

\section{References}

1. Lewis, J.R.; Eggermont, C.J.; Schousboe, J.T.; Lim, W.H.; Wong, G.; Khoo, B.; Sim, M.; Yu, M.; Ueland, T.; Bollerslev, J.; et al. Association Between Abdominal Aortic Calcification, Bone Mineral Density, and Fracture in Older Women. J. Bone Min. Res. 2019, 34, 2052-2060. [CrossRef]

2. $\quad$ Park, J.; Yoon, Y.E.; Kim, K.M.; Hwang, I.-C.; Lee, W.; Cho, G.-Y. Prognostic Value of Lower Bone Mineral Density in Predicting Adverse Cardiovascular Disease in Asian Women. Heart 2021, 107, 1040-1046. [CrossRef] [PubMed]

3. Muñoz-Torres, M.; Reyes-García, R.; García-Martin, A.; Jiménez-Moleón, J.J.; Gonzalez-Ramírez, A.R.; Lara-Villoslada, M.J.; Moreno, P.R. Ischemic Heart Disease Is Associated with Vertebral Fractures in Patients with Type 2 Diabetes Mellitus. J. Diabetes Investig. 2013, 4, 310-315. [CrossRef]

4. Bielecka-Dabrowa, A.; Ebner, N.; Dos Santos, M.R.; Ishida, J.; Hasenfuss, G.; von Haehling, S. Cachexia, Muscle Wasting, and Frailty in Cardiovascular Disease. Eur. J. Heart Fail. 2020, 22, 2314-2326. [CrossRef] [PubMed]

5. Liu, H.; Chen, A. Roles of Sleep Deprivation in Cardiovascular Dysfunctions. Life Sci. 2019, 219, 231-237. [CrossRef]

6. Pluta, R. Brain Ischemia as a Bridge to Alzheimer's Disease. Neural Regen Res. 2021, 17, 791-792. [CrossRef] [PubMed]

7. World Health Organization. The ICD-10 Classification of Mental and Behavioural Disorders: Clinical Descriptions and Diagnostic Guidelines; World Health Organization: Geneva, Switzerland, 1992.

8. Brookmeyer, R.; Johnson, E.; Ziegler-Graham, K.; Arrighi, H.M. Forecasting the Global Burden of Alzheimer's Disease. Alzheimers Dement. 2007, 3, 186-191. [CrossRef]

9. Mielke, M.M.; Vemuri, P.; Rocca, W.A. Clinical Epidemiology of Alzheimer's Disease: Assessing Sex and Gender Differences. Clin. Epidemiol. 2014, 6, 37-48. [CrossRef]

10. Lee, J.-Y.; Chang, S.M.; Jang, H.-S.; Chang, J.S.; Suh, G.-H.; Jung, H.-Y.; Jeon, H.-J.; Cho, M.J. Illiteracy and the Incidence of Alzheimer's Disease in the Yonchon County Survey, Korea. Int. Psychogeriatr. 2008, 20, 976-985. [CrossRef]

11. Cataldo, J.K.; Prochaska, J.J.; Glantz, S.A. Cigarette Smoking Is a Risk Factor for Alzheimer's Disease: An Analysis Controlling for Tobacco Industry Affiliation. J. Alzheimers Dis. 2010, 19, 465-480. [CrossRef]

12. Beydoun, M.A.; Beydoun, H.A.; Wang, Y. Obesity and Central Obesity as Risk Factors for Incident Dementia and Its Subtypes: A Systematic Review and Meta-Analysis. Obes. Rev. 2008, 9, 204-218. [CrossRef] [PubMed]

13. Kivipelto, M.; Ngandu, T.; Fratiglioni, L.; Viitanen, M.; Kåreholt, I.; Winblad, B.; Helkala, E.-L.; Tuomilehto, J.; Soininen, H.; Nissinen, A. Obesity and Vascular Risk Factors at Midlife and the Risk of Dementia and Alzheimer Disease. Arch. Neurol. 2005, 62, 1556-1560. [CrossRef]

14. Arvanitakis, Z.; Wilson, R.S.; Bienias, J.L.; Evans, D.A.; Bennett, D.A. Diabetes Mellitus and Risk of Alzheimer Disease and Decline in Cognitive Function. Arch. Neurol. 2004, 61, 661-666. [CrossRef] [PubMed]

15. Menta, B.W.; Swerdlow, R.H. An Integrative Overview of Non-Amyloid and Non-Tau Pathologies in Alzheimer's Disease. Neurochem. Res. 2019, 44, 12-21. [CrossRef] [PubMed] 
16. Stakos, D.A.; Stamatelopoulos, K.; Bampatsias, D.; Sachse, M.; Zormpas, E.; Vlachogiannis, N.I.; Tual-Chalot, S.; Stellos, K. The Alzheimer's Disease Amyloid-Beta Hypothesis in Cardiovascular Aging and Disease: JACC Focus Seminar. J. Am. Coll. Cardiol. 2020, 75, 952-967. [CrossRef]

17. Wanleenuwat, P.; Iwanowski, P.; Kozubski, W. Alzheimer's Dementia: Pathogenesis and Impact of Cardiovascular Risk Factors on Cognitive Decline. Postgrad. Med. 2019, 131, 415-422. [CrossRef] [PubMed]

18. Kalaria, R.N. The Pathology and Pathophysiology of Vascular Dementia. Neuropharmacology 2018, 134, 226-239. [CrossRef]

19. Iadecola, C. The Pathobiology of Vascular Dementia. Neuron 2013, 80, 844-866. [CrossRef]

20. Armstrong, R.A. Risk Factors for Alzheimer Disease. Factores de Riesgo Para La Enfermedad de Alzheimer. Brain Nerve 2019, 57, 87-105.

21. Kalaria, R.N.; Hedera, P. Differential Degeneration of the Cerebral Microvasculature in Alzheimer's Disease. NeuroRep. 1995, 6, 477-480. [CrossRef]

22. Lamar, M.; Boots, E.A.; Arfanakis, K.; Barnes, L.L.; Schneider, J.A. Common Brain Structural Alterations Associated with Cardiovascular Disease Risk Factors and Alzheimer's Dementia: Future Directions and Implications. Neuropsychol. Rev. 2020, 30, 546-557. [CrossRef] [PubMed]

23. Fredman, G. Resolving Atherosclerosis and Alzheimer Disease. Nat. Rev. Cardiol. 2019, 16, 259-260. [CrossRef] [PubMed]

24. Ray, M.; Ruan, J.; Zhang, W. Variations in the Transcriptome of Alzheimer's Disease Reveal Molecular Networks Involved in Cardiovascular Diseases. Genome Biol. 2008, 9, R148. [CrossRef] [PubMed]

25. Kunkle, B.W.; Grenier-Boley, B.; Sims, R.; Bis, J.C.; Damotte, V.; Naj, A.C.; Boland, A.; Vronskaya, M.; van der Lee, S.J.; Amlie-Wolf, A.; et al. Genetic Meta-Analysis of Diagnosed Alzheimer's Disease Identifies New Risk Loci and Implicates A $\beta$, Tau, Immunity and Lipid Processing. Nat. Genet. 2019, 51, 414-430. [CrossRef]

26. Purgatorio, R.; Gambacorta, N.; de Candia, M.; Catto, M.; Rullo, M.; Pisani, L.; Nicolotti, O.; Altomare, C.D. First-in-Class Isonipecotamide-Based Thrombin and Cholinesterase Dual Inhibitors with Potential for Alzheimer Disease. Molecules 2021, 26, 5208. [CrossRef]

27. Henderson, A.S. The Risk Factors for Alzheimer's Disease: A Review and a Hypothesis. Acta Psychiatr. Scand. 1988, 78, 257-275. [CrossRef]

28. Hjelm, C.; Broström, A.; Dahl, A.; Johansson, B.; Fredrikson, M.; Strömberg, A. Factors Associated with Increased Risk for Dementia in Individuals Age 80 Years or Older with Congestive Heart Failure. J. Cardiovasc. Nurs. 2014, 29, 82-90. [CrossRef]

29. Zhang, X.; Le, W. Pathological Role of Hypoxia in Alzheimer's Disease. Exp. Neurol. 2010, 223, 299-303. [CrossRef]

30. Jeong, H.; Mason, S.P.; Barabási, A.L.; Oltvai, Z.N. Lethality and Centrality in Protein Networks. Nature 2001, 411, 41-42. [CrossRef]

31. Barrett, T.; Wilhite, S.E.; Ledoux, P.; Evangelista, C.; Kim, I.F.; Tomashevsky, M.; Marshall, K.A.; Phillippy, K.H.; Sherman, P.M.; Holko, M.; et al. NCBI GEO: Archive for Functional Genomics Data Sets-Update. Nucleic Acids Res. 2013, 41, D991-D995. [CrossRef]

32. Szklarczyk, D.; Gable, A.L.; Lyon, D.; Junge, A.; Wyder, S.; Huerta-Cepas, J.; Simonovic, M.; Doncheva, N.T.; Morris, J.H.; Bork, P.; et al. STRING V11: Protein-Protein Association Networks with Increased Coverage, Supporting Functional Discovery in Genome-Wide Experimental Datasets. Nucleic Acids Res. 2019, 47, D607-D613. [CrossRef] [PubMed]

33. Shannon, P.; Markiel, A.; Ozier, O.; Baliga, N.S.; Wang, J.T.; Ramage, D.; Amin, N.; Schwikowski, B.; Ideker, T. Cytoscape: A Software Environment for Integrated Models of Biomolecular Interaction Networks. Genome Res. 2003, 13, 2498-2504. [CrossRef] [PubMed]

34. Bader, G.D.; Hogue, C.W. An Automated Method for Finding Molecular Complexes in Large Protein Interaction Networks. BMC Bioinform. 2003, 4, 1-27. [CrossRef] [PubMed]

35. Tang, Y.; Li, M.; Wang, J.; Pan, Y.; Wu, F.-X. CytoNCA: A Cytoscape Plugin for Centrality Analysis and Evaluation of Protein Interaction Networks. Biosystems 2015, 127, 67-72. [CrossRef]

36. Piñero, J.; Bravo, À.; Queralt-Rosinach, N.; Gutiérrez-Sacristán, A.; Deu-Pons, J.; Centeno, E.; García-García, J.; Sanz, F.; Furlong, L.I. DisGeNET: A Comprehensive Platform Integrating Information on Human Disease-Associated Genes and Variants. Nucleic Acids Res. 2017, 45, D833-D839. [CrossRef]

37. Norgren, L.; Hiatt, W.R.; Dormandy, J.A.; Nehler, M.R.; Harris, K.A.; Fowkes, F.G.R.; TASC II Working Group. Inter-Society Consensus for the Management of Peripheral Arterial Disease (TASC II). J. Vasc. Surg. 2007, 45 (Suppl. S), S5-S67. [CrossRef]

38. Andújar-Vera, F.; García-Fontana, C.; Lozano-Alonso, S.; González-Salvatierra, S.; Iglesias-Baena, I.; Muñoz-Torres, M.; GarcíaFontana, B. Association between Oxidative-Stress-Related Markers and Calcified Femoral Artery in Type 2 Diabetes Patients. J. Pharm. Biomed. Anal. 2020, 190, 113535. [CrossRef]

39. Steenman, M.; Espitia, O.; Maurel, B.; Guyomarch, B.; Heymann, M.-F.; Pistorius, M.-A.; Ory, B.; Heymann, D.; Houlgatte, R.; Gouëffic, Y.; et al. Identification of Genomic Differences among Peripheral Arterial Beds in Atherosclerotic and Healthy Arteries. Sci. Rep. 2018, 8, 3940. [CrossRef]

40. Valanti, E.-K.; Dalakoura-Karagkouni, K.; Siasos, G.; Kardassis, D.; Eliopoulos, A.G.; Sanoudou, D. Advances in Biological Therapies for Dyslipidemias and Atherosclerosis. Metabolism 2021, 116, 154461. [CrossRef]

41. Lee, S.; Parekh, T.; King, S.M.; Reed, B.; Chui, H.C.; Krauss, R.M.; Yassine, H.N. Low-Density Lipoprotein Particle Size Subfractions and Cerebral Amyloidosis. J. Alzheimers Dis. 2019, 68, 983-990. [CrossRef] 
42. Chatterjee, P.; Lim, W.L.F.; Shui, G.; Gupta, V.B.; James, I.; Fagan, A.M.; Xiong, C.; Sohrabi, H.R.; Taddei, K.; Brown, B.M.; et al. Plasma Phospholipid and Sphingolipid Alterations in Presenilin1 Mutation Carriers: A Pilot Study. J. Alzheimers Dis. 2016, 50, 887-894. [CrossRef] [PubMed]

43. Button, E.B.; Boyce, G.K.; Wilkinson, A.; Stukas, S.; Hayat, A.; Fan, J.; Wadsworth, B.J.; Robert, J.; Martens, K.M.; Wellington, C.L. ApoA-I Deficiency Increases Cortical Amyloid Deposition, Cerebral Amyloid Angiopathy, Cortical and Hippocampal Astrogliosis, and Amyloid-Associated Astrocyte Reactivity in APP/PS1 Mice. Alzheimers Res. 2019, 11, 44. [CrossRef] [PubMed]

44. Xing, Y.; Tang, Y.; Zhao, L.; Wang, Q.; Qin, W.; Zhang, J.-L.; Jia, J. Plasma Ceramides and Neuropsychiatric Symptoms of Alzheimer's Disease. J. Alzheimers Dis. 2016, 52, 1029-1035. [CrossRef]

45. Kim, S.H.; Yang, J.S.; Lee, J.C.; Lee, J.-Y.; Lee, J.-Y.; Kim, E.; Moon, M.H. Lipidomic Alterations in Lipoproteins of Patients with Mild Cognitive Impairment and Alzheimer's Disease by Asymmetrical Flow Field-Flow Fractionation and Nanoflow Ultrahigh Performance Liquid Chromatography-Tandem Mass Spectrometry. J. Chromatogr. A. 2018, 1568, 91-100. [CrossRef]

46. Proitsi, P.; Kim, M.; Whiley, L.; Simmons, A.; Sattlecker, M.; Velayudhan, L.; Lupton, M.K.; Soininen, H.; Kloszewska, I.; Mecocci, P.; et al. Association of Blood Lipids with Alzheimer's Disease: A Comprehensive Lipidomics Analysis. Alzheimers Dement. 2017, 13, 140-151. [CrossRef]

47. Mejías-Trueba, M.; Pérez-Moreno, M.A.; Fernández-Arche, M.Á. Systematic Review of the Efficacy of Statins for the Treatment of Alzheimer's Disease. Clin. Med. Lond. 2018, 18, 54-61. [CrossRef]

48. Chaaba, R.; Attia, N.; Hammami, S.; Smaoui, M.; Ben Hamda, K.; Mahjoub, S.; Hammami, M. Association between Apolipoprotein E Polymorphism, Lipids, and Coronary Artery Disease in Tunisian Type 2 Diabetes. J. Clin. Lipidol. 2008, 2, 360-364. [CrossRef] [PubMed]

49. Gao, C.; Fu, X.; Chu, Q.; Li, J.; Shu, G. Relationship Between the ApoE Gene Polymorphism and Type 2 Diabetes Mellitus Complications. Genet. Test. Mol. Biomark. 2021, 25, 111-115. [CrossRef] [PubMed]

50. Luo, J.-Q.; Ren, H.; Banh, H.L.; Liu, M.-Z.; Xu, P.; Fang, P.-F.; Xiang, D.-X. The Associations between Apolipoprotein E Gene Epsilon2/Epsilon3/Epsilon4 Polymorphisms and the Risk of Coronary Artery Disease in Patients with Type 2 Diabetes Mellitus. Front Physiol. 2017, 8, 1031. [CrossRef] [PubMed]

51. Borovecki, F.; Klepac, N.; Muck-Seler, D.; Hajnsek, S.; Mubrin, Z.; Pivac, N. Unraveling the Biological Mechanisms in Alzheimer's Disease-Lessons from Genomics. Prog Neuropsychopharmacol. Biol. Psychiatry 2011, 35, 340-347. [CrossRef] [PubMed]

52. Chen, Y.-C.; Chiu, Y.-J.; Lin, C.-H.; Hsu, W.-C.; Wu, J.-L.; Huang, C.-H.; Lin, C.-W.; Yao, C.-F.; Huang, H.-J.; Lo, Y.-S.; et al. Indole Compound NC009-1 Augments APOE and TRKA in Alzheimer's Disease Cell and Mouse Models for Neuroprotection and Cognitive Improvement. J. Alzheimers Dis. 2019, 67, 737-756. [CrossRef] [PubMed]

53. Kara, E.; Marks, J.D.; Fan, Z.; Klickstein, J.A.; Roe, A.D.; Krogh, K.A.; Wegmann, S.; Maesako, M.; Luo, C.C.; Mylvaganam, R.; et al. Isoform- and Cell Type-Specific Structure of Apolipoprotein E Lipoparticles as Revealed by a Novel Forster Resonance Energy Transfer Assay. J. Biol. Chem. 2017, 292, 14720-14729. [CrossRef] [PubMed]

54. McFall, G.P.; Bäckman, L.; Dixon, R.A. Nuances in Alzheimer's Genetic Risk Reveal Differential Predictions of Non-Demented Memory Aging Trajectories: Selective Patterns by APOE Genotype and Sex. Curr. Alzheimer Res. 2019, 16, 302-315. [CrossRef] [PubMed]

55. Utermann, G. Alzheimer's Disease. The Apolipoprotein E Connection. Curr. Biol. 1994, 4, 362-365. [CrossRef]

56. Yamazaki, Y.; Zhao, N.; Caulfield, T.R.; Liu, C.-C.; Bu, G. Apolipoprotein E and Alzheimer Disease: Pathobiology and Targeting Strategies. Nat. Rev. Neurol. 2019, 15, 501-518. [CrossRef]

57. Marais, A.D. Apolipoprotein E in Lipoprotein Metabolism, Health and Cardiovascular Disease. Patholology 2019, 51, 165-176. [CrossRef]

58. Borth, W. Alpha 2-Macroglobulin, a Multifunctional Binding Protein with Targeting Characteristics. FASEB J. 1992, 6, 3345-3353 [CrossRef]

59. Varma, V.R.; Varma, S.; An, Y.; Hohman, T.J.; Seddighi, S.; Casanova, R.; Beri, A.; Dammer, E.B.; Seyfried, N.T.; Pletnikova, O.; et al. Alpha-2 Macroglobulin in Alzheimer's Disease: A Marker of Neuronal Injury through the RCAN1 Pathway. Mol. Psychiatry 2017, 22, 13-23. [CrossRef]

60. Yoshino, S.; Fujimoto, K.; Takada, T.; Kawamura, S.; Ogawa, J.; Kamata, Y.; Kodera, Y.; Shichiri, M. Molecular Form and Concentration of Serum A2-Macroglobulin in Diabetes. Sci. Rep. 2019, 9, 12927. [CrossRef]

61. Nezu, T.; Hosomi, N.; Aoki, S.; Deguchi, K.; Masugata, H.; Ichihara, N.; Ohyama, H.; Ohtsuki, T.; Kohno, M.; Matsumoto, M. Alpha2-Macroglobulin as a Promising Biomarker for Cerebral Small Vessel Disease in Acute Ischemic Stroke Patients. J. Neurol. 2013, 260, 2642-2649. [CrossRef]

62. Jones, S.E.; Jomary, C. Clusterin. Int. J. Biochem. Cell Biol. 2002, 34, 427-431. [CrossRef]

63. Wong, P.; Taillefer, D.; Lakins, J.; Pineault, J.; Chader, G.; Tenniswood, M. Molecular Characterization of Human TRPM2/Clusterin, a Gene Associated with Sperm Maturation, Apoptosis and Neurodegeneration. Eur. J. Biochem. 1994, 221, 917-925. [CrossRef] [PubMed]

64. Al Nakouzi, N.; Wang, C.K.; Beraldi, E.; Jager, W.; Ettinger, S.; Fazli, L.; Nappi, L.; Bishop, J.; Zhang, F.; Chauchereau, A.; et al. Clusterin Knockdown Sensitizes Prostate Cancer Cells to Taxane by Modulating Mitosis. EMBO Mol. Med. 2016, 8, 761-778. [CrossRef] [PubMed] 
65. Lin, C.-C.; Tsai, P.; Sun, H.-Y.; Hsu, M.-C.; Lee, J.-C.; Wu, I.-C.; Tsao, C.-W.; Chang, T.-T.; Young, K.-C. Apolipoprotein, J., A Glucose-Upregulated Molecular Chaperone, Stabilizes Core and NS5A to Promote Infectious Hepatitis C Virus Virion Production. J. Hepatol. 2014, 61, 984-993. [CrossRef] [PubMed]

66. Trougakos, I.P.; Gonos, E.S. Regulation of Clusterin/Apolipoprotein J, a Functional Homologue to the Small Heat Shock Proteins, by Oxidative Stress in Ageing and Age-Related Diseases. Free Radic. Res. 2006, 40, 1324-1334. [CrossRef]

67. Wong, P.; Pineault, J.; Lakins, J.; Taillefer, D.; Léger, J.; Wang, C.; Tenniswood, M. Genomic Organization and Expression of the Rat TRPM-2 (Clusterin) Gene, a Gene Implicated in Apoptosis. J. Biol. Chem. 1993, 268, 5021-5031. [CrossRef]

68. Lambert, J.-C.; Heath, S.; Even, G.; Campion, D.; Sleegers, K.; Hiltunen, M.; Combarros, O.; Zelenika, D.; Bullido, M.J.; Tavernier B.; et al. Genome-Wide Association Study Identifies Variants at CLU and CR1 Associated with Alzheimer's Disease. Nat. Genet. 2009, 41, 1094-1099. [CrossRef]

69. Foster, E.M.; Dangla-Valls, A.; Lovestone, S.; Ribe, E.M.; Buckley, N.J. Clusterin in Alzheimer's Disease: Mechanisms, Genetics, and Lessons From Other Pathologies. Front Neurosci. 2019, 13, 164. [CrossRef]

70. May, P.C.; Finch, C.E. Sulfated Glycoprotein 2: New Relationships of This Multifunctional Protein to Neurodegeneration. Trends Neurosci. 1992, 15, 391-396. [CrossRef]

71. Roheim, P.S.; Carey, M.; Forte, T.; Vega, G.L. Apolipoproteins in Human Cerebrospinal Fluid. Proc. Natl. Acad. Sci. USA 1979, 76, 4646-4649. [CrossRef]

72. May, P.C.; Lampert-Etchells, M.; Johnson, S.A.; Poirier, J.; Masters, J.N.; Finch, C.E. Dynamics of Gene Expression for a Hippocampal Glycoprotein Elevated in Alzheimer's Disease and in Response to Experimental Lesions in Rat. Neuron 1990, 5, 831-839. [CrossRef]

73. Calero, M.; Rostagno, A.; Matsubara, E.; Zlokovic, B.; Frangione, B.; Ghiso, J. Apolipoprotein J (Clusterin) and Alzheimer's Disease. Microsc. Res. Tech. 2000, 50, 305-315. [CrossRef]

74. Zlokovic, B.V.; Martel, C.L.; Matsubara, E.; McComb, J.G.; Zheng, G.; McCluskey, R.T.; Frangione, B.; Ghiso, J. Glycoprotein 330/Megalin: Probable Role in Receptor-Mediated Transport of Apolipoprotein J Alone and in a Complex with Alzheimer Disease Amyloid Beta at the Blood-Brain and Blood-Cerebrospinal Fluid Barriers. Proc. Natl. Acad. Sci. USA 1996, 93, 4229-4234. [CrossRef]

75. Ghiso, J.; Matsubara, E.; Koudinov, A.; Choi-Miura, N.H.; Tomita, M.; Wisniewski, T.; Frangione, B. The Cerebrospinal-Fluid Soluble Form of Alzheimer's Amyloid $\beta$ Is Complexed to SP-40,40 (Apolipoprotein J), an Inhibitor of the Complement MembraneAttack Complex. Biochem. J. 1993, 293, 27-30. [CrossRef]

76. DeMattos, R.B.; Cirrito, J.R.; Parsadanian, M.; May, P.C.; O’Dell, M.A.; Taylor, J.W.; Harmony, J.A.K.; Aronow, B.J.; Bales, K.R.; Paul, S.M.; et al. ApoE and Clusterin Cooperatively Suppress A $\beta$ Levels and Deposition: Evidence That ApoE Regulates Extracellular A $\beta$ Metabolism In Vivo. Neuron 2004, 41, 193-202. [CrossRef]

77. Bell, R.D.; Sagare, A.P.; Friedman, A.E.; Bedi, G.S.; Holtzman, D.M.; Deane, R.; Zlokovic, B.V. Transport Pathways for Clearance of Human Alzheimer's Amyloid $\beta$-Peptide and Apolipoproteins E and J in the Mouse Central Nervous System. J. Cereb. Blood Flow Metab. 2007, 27, 909-918. [CrossRef] [PubMed]

78. Bai, F.; Shi, Y.; Yuan, Y.; Xie, C.; Zhang, Z. Immunity Factor Contributes to Altered Brain Functional Networks in Individuals at Risk for Alzheimer's Disease: Neuroimaging-Genetic Evidence. Brain Behav. Immun. 2016, 56, 84-95. [CrossRef]

79. Schrijvers, E.M.C.; Koudstaal, P.J.; Hofman, A.; Breteler, M.M.B. Plasma Clusterin and the Risk of Alzheimer Disease. JAMA 2011, 305, 1322-1326. [CrossRef]

80. Yang, C.; Wang, H.; Li, C.; Niu, H.; Luo, S.; Guo, X. Association between Clusterin Concentration and Dementia: A Systematic Review and Meta-Analysis. Metab. Brain Dis. 2019, 34, 129-140. [CrossRef]

81. Hsu, J.-L.; Lee, W.-J.; Liao, Y.-C.; Wang, S.-J.; Fuh, J.-L. The Clinical Significance of Plasma Clusterin and A $\beta$ in the Longitudinal Follow-up of Patients with Alzheimer's Disease. Alzheimers Res. 2017, 9, 91. [CrossRef]

82. Bradley, D.; Blaszczak, A.; Yin, Z.; Liu, J.; Joseph, J.J.; Wright, V.; Anandani, K.; Needleman, B.; Noria, S.; Renton, D.; et al Clusterin Impairs Hepatic Insulin Sensitivity and Adipocyte Clusterin Associates With Cardiometabolic Risk. Diabetes Care 2019, 42, 466-475. [CrossRef] [PubMed]

83. Lackey, D.E.; Burk, D.H.; Ali, M.R.; Mostaedi, R.; Smith, W.H.; Park, J.; Scherer, P.E.; Seay, S.A.; McCoin, C.S.; Bonaldo, P.; et al. Contributions of Adipose Tissue Architectural and Tensile Properties toward Defining Healthy and Unhealthy Obesity. Am. J. Physiol. Endocrinol. Metab. 2014, 306, E233-E246. [CrossRef] [PubMed]

84. Lin, D.; Chun, T.-H.; Kang, L. Adipose Extracellular Matrix Remodelling in Obesity and Insulin Resistance. Biochem. Pharm. 2016 119, 8-16. [CrossRef] [PubMed]

85. Won, J.C.; Park, C.-Y.; Oh, S.W.; Lee, E.S.; Youn, B.-S.; Kim, M.-S. Plasma Clusterin (ApoJ) Levels Are Associated with Adiposity and Systemic Inflammation. PLoS ONE 2014, 9, e103351. [CrossRef]

86. Kim, H.-J.; Yoo, E.-K.; Kim, J.-Y.; Choi, Y.-K.; Lee, H.-J.; Kim, J.-K.; Jeoung, N.H.; Lee, K.-U.; Park, I.-S.; Min, B.-H.; et al. Protective Role of Clusterin/ Apolipoprotein J against Neointimal Hyperplasia via Antiproliferative Effect on Vascular Smooth Muscle Cells and Cytoprotective Effect on Endothelial Cells. Arter. Thromb Vasc. Biol. 2009, 29, 1558-1564. [CrossRef]

87. Baralla, A.; Sotgiu, E.; Deiana, M.; Pasella, S.; Pinna, S.; Mannu, A.; Canu, E.; Sotgiu, G.; Ganau, A.; Zinellu, A.; et al. Plasma Clusterin and Lipid Profile: A Link with Aging and Cardiovascular Diseases in a Population with a Consistent Number of Centenarians. PLoS ONE 2015, 10, e0128029. [CrossRef] 
88. Park, S.; Mathis, K.W.; Lee, I.K. The Physiological Roles of Apolipoprotein J/Clusterin in Metabolic and Cardiovascular Diseases. Rev. Endocr. Metab. Disord. 2014, 15, 45-53. [CrossRef]

89. Wittwer, J.; Bradley, D. Clusterin and Its Role in Insulin Resistance and the Cardiometabolic Syndrome. Front Immunol. 2021, 12, 612496. [CrossRef]

90. Güleç, G.U.; Turgut, Y.B.; Turgut, M. Acute phase proteins. In Reference Module in Biomedical Sciences; Elsevier: Amsterdam, The Netherlands, 2021; ISBN 978-0-12-801238-3.

91. Song, I.-U.; Kim, Y.-D.; Chung, S.-W.; Cho, H.-J. Association between Serum Haptoglobin and the Pathogenesis of Alzheimer's Disease. Intern. Med. 2015, 54, 453-457. [CrossRef]

92. Zhu, C.-J.; Jiang, G.-X.; Chen, J.-M.; Zhou, Z.-M.; Cheng, Q. Serum Haptoglobin in Chinese Patients with Alzheimer's Disease and Mild Cognitive Impairment: A Case-Control Study. Brain Res. Bull. 2018, 137, 301-305. [CrossRef] 